\title{
Patients With Rett Syndrome Sustain Low-Energy Fractures
}

\author{
GITTE ROENDE, KIRSTINE RAVN, KATHRINE FUGLSANG, HENRIK ANDERSEN, AAGE VESTERGAARD, \\ KAREN BRØNDUM-NIELSEN, JENS-ERIK BECK JENSEN, AND JYTTE BIEBER NIELSEN
}

\author{
Center for Rett Syndrome [G.R., K.R., K.F., J.B.N.], Genetic Counseling Clinic [K.B.-N.], Kennedy Center, Glostrup 2600, Denmark; \\ School of Physiotherapy [H.A.], Metropolitan University College, Copenhagen 2200, Denmark; Department of Radiology [A.V.], \\ Department of Endocrinology [J.-E.B.J.], Hvidovre Hospital, Hvidovre 2650, Denmark
}

\begin{abstract}
We present the first case-control study addressing both fracture occurrence and fracture mechanisms in Rett syndrome (RTT). Two previous studies have shown increased fracture risk in RTT. This was also our hypothesis regarding the Danish RTT population. Therefore, we investigated risk factors associated with low-energy trauma and the association to methyl-CpG-binding protein 2 (MECP2) mutations. A total of 61 female patients with RTT and 122 healthy controls matched according to age and pubertal/ menopause status were examined by questionnaires, bone biochemical markers in blood, and clinical and x-ray evaluations. National register search on fracture diagnoses was done to obtain complete fracture histories. Our results showed that patients with RTT sustained significantly more low-energy fractures from early age compared with controls, even though overall fracture occurrence apparently was not increased. Low-energy fractures were significantly associated with less mobility and lack of ambulation. Associations with $M E C P 2$ mutations or epilepsy were not demonstrated, contrary to previous findings. Blood biochemistry indicated a possible need for D vitamin supplementation in RTT. Our study casts light on fracture occurrence in RTT and points to a need for future research in bone development and fracture risk to establish directions for improved prevention and treatment of low-energy fractures in RTT. (Pediatr Res 69: 359-364, 2011)
\end{abstract}

$\mathrm{R}$ ett syndrome (RTT) is a severe neurodevelopmental disorder, affecting mainly females because of de novo mutations in the X-linked gene, methyl-CpG-binding protein 2 (MECP2) located at Xq28 (1). RTT has a worldwide distribution with a prevalence of 1:10,000 in Denmark (2). Classical and atypical forms of RTT have been described $(3,4)$ giving a broad spectrum of symptoms (5).

Most females with RTT are growth retarded (6), but descriptions of other bone-related symptoms such as fractures and bone mass are not included in clinical scales evaluating severity scores in RTT (7). One study showed that patients with RTT are at almost 4-fold increased risk of getting a fracture (8).

Low bone mass is seen in RTT (9-14), and an association between low bone mass and fractures in RTT has been found in three studies $(9,13,15)$. Furthermore, a diagnosis of epilepsy and treatment with antiepileptic drugs (AED) have been as-

Received July 6, 2010; accepted October 31, 2010.

Correspondence: Gitte Roende, M.D., Center for Rett Syndrome, Kennedy Center, Gl. Landevej 7, 2600 Glostrup, Denmark; e-mail address: gitte@ roende.org

Supported by Bevica Fonden, Forskningsfonden vedrørende medfødte sygdomme under Vanførefonden, Danske Banks Fond, Elsass Fonden, Fonden til Lægevidenskabens Fremme. sociated with fracture occurrence in RTT $(8,9,16)$, whereas an association to mobility is less clear $(8,9)$.

The aim of this case-control study was to investigate the prevalence of fractures in the Danish patients with RTT with known MECP2 mutations. We wanted to compare fracture mechanism and age at first fracture event in patients with RTT with healthy controls. Furthermore, we wanted to examine whether risk factors such as mobility status, fall tendency, epilepsy, antiepileptic treatment, and vitamin D status were associated with fracture occurrence within RTT. Our hypothesis was that an increased risk of fractures was present in patients with RTT, possibly related to $M E C P 2$ mutation types and risk factors associated with low-energy trauma.

\section{METHODS}

Participants. Patients were recruited from the Danish Centre for Rett syndrome at the Kennedy Center. Only females with RTT and a MECP2 mutation were included for examination. Healthy controls were matched according to sex, age, and pubertal/menopausal status and recruited from Hvidovre municipality in Copenhagen. Possible controls were found searching the Central Person Registry [containing identification number and other civic data on every inhabitant in Denmark; Fig. 1, Table 1 (17), and Table 2].

Measurements. Fracture occurrence was evaluated by means of questionnaire, national register research, and x-ray examinations. Fractures were classified into low-energy fractures (spontaneous fractures, no known trauma or falls within ones height) and high-energy fractures (falls from one level to another or activity involving speed). Only specified fractures of the spine, the upper arm, forearm, upper leg, and lower leg were compared. Possible risk factors were examined with questionnaire, blood sampling, and clinical evaluations. Censoring date for fractures was examination date.

The MECP2 mutations were divided into four different mutation types, based on the expected functionality of MECP2: mutations leading to early truncation before nuclear localization signal (NLS), mutations leading to late truncation after the NLS, C-terminal mutations, and missense mutations.

Personal caregivers for patients with RTT and controls filled in a validated composite questionnaire with different items including fracture age, location and mechanism, supplemented with items on fall tendency within the past 6 mo, current average mobility and weight bearing when walking, standing and sitting, best ability to walk ever, a diagnosis of epilepsy, current seizures, and current and former treatment with AED regarding patients with RTT. Of these, $10(16 \%)$ randomly selected patients had their supplementary questionnaire items validated by repeating their answers concerning risk factors $2-3$ wk later. Nonresponders were contacted in case of missing information on questionnaire items and complete answers were obtained.

A reported fracture was confirmed by a history of x-ray, operation, or treatment with casts or splints in a standardized way. When fractures were reported in the questionnaire, medical records were retrieved to verify fracture diagnosis. A registry search of the National Patients Registry (NPR) (18) for

Abbreviations: AED, antiepileptic drugs; MECP2, methyl-CpG-binding protein 2 gene; NLS, nuclear localization signal; NPR, National Patients Registry; RTT, Rett syndrome 


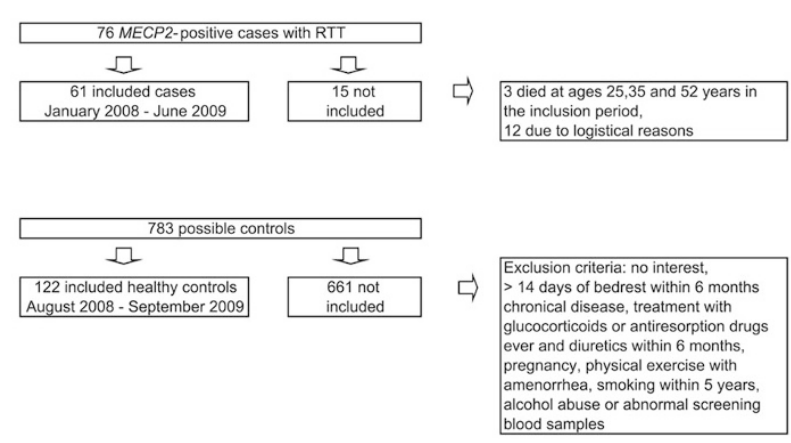

Figure 1. Inclusion diagram for cases and controls.

Table 1. Case-control characteristics

\begin{tabular}{lcc}
\hline \multicolumn{1}{c}{ Characteristics } & $\begin{array}{c}\text { Included Rett cases** } \\
(n=61)\end{array}$ & $\begin{array}{c}\text { Included controls } \\
(n=122)\end{array}$ \\
\hline Median age in decimals, (range) & $20.1(6.0-60.6)$ & $20.2(6.0-60.9)$ \\
Pubertal stage $<20 \mathrm{y}, n(\%) \dagger$ & $16(26.2)$ & $29(23.8)$ \\
Tanner stage 1 & $5(8.2)$ & $14(11.5)$ \\
Tanner stage 2 & $3(4.9)$ & $7(5.7)$ \\
Tanner stage 3 & $3(4.9)$ & $6(4.9)$ \\
Tanner stage 4 & $3(4.9)$ & $4(3.3)$ \\
Tanner stage 5 & $31(50.8)$ & $62(50.8)$ \\
$\geq 20$ y, $n(\%)$ & & \\
Menstruation, $n(\%)$ & $21(34.4)$ & $42(34.4)$ \\
No, $<20$ y & $9(14.8)$ & $18(14.8)$ \\
Yes, $<20$ y & $29(47.5)$ & $58(47.5)$ \\
Yes, $>20$ y & $2(3.3)$ & $4(3.3)$ \\
No, $>20$ y &
\end{tabular}

* Not-included Rett cases: $n=15$. Median age in decimals (range): 25.9 $(12.8-52.9)$

$\dagger$ Reference 17.

relevant fracture diagnoses among cases and controls was completed in January 2010 to enhance full fracture data sampling.

We retrieved all data according to fracture diagnoses concerning fractures of the thoracal and lumbal spine, the humeral bones, the ulnar and radial bones, the femoral bone, and the tibial, fibulal, and patellal bones within both the ICD-8 and ICD-10 (http://www.who.int/classifications/icd).

Cases were examined with anteroposterior and lateral projections of $\mathrm{x}$-rays of the thoracal-lumbal spine, unless a high-quality anteroposterior and lateral $\mathrm{x}$-ray examination had been performed within 1 year before examination date and could be obtained. An experienced child radiologist evaluated the radiographs according to Genant's semiquantitative assessment (19). Controls were examined by Vertebral Fracture Assessment (VFA; Hologic Discovery A, Hologic, Inc., Bedford, MA) if they are older than $50 \mathrm{y}$ or if they had a previous history of possible vertebral fractures. VFA is a lateral projected DXA (dual-energy x-ray absorptiometry) scan of the spine with low-radiation exposure applied in screening of vertebral fractures (20). If not conclusive, an $\mathrm{x}$-ray was taken as for cases.

Fasting blood samples were analyzed to determine red and white blood cell count, renal and liver function, thyroid status, and calcium metabolic parameters such as calcium, PTH, and 25-OH vitamin D (Immunoassay, DiaSorin S.p.A., Sallugia, Vercelli, Italy) status in cases and controls. A value for $25-\mathrm{OH}$ vitamin $\mathrm{D}>50 \mathrm{nmol} / \mathrm{L}$ was accepted as normal.

Statistical analysis. Case-control characteristics, MECP2 mutation data, fracture persons, and fracture events were summarized in total numbers and percentages. Median and range was used when data were not normally distributed. Because some cases and controls had more than one fracture, both fracture persons and fracture events were compared. Categorical data regarding low energy and total fracture persons and fracture events among cases and controls were sufficient in numbers to be compared using OR with a 95\%-CI. To test further, we also applied $\chi^{2}$ tests for large sample sizes and Fisher's exact test when expected cell counts were $<5$ for comparing number of persons with fractures among cases and controls. Comparison of potential risk factors among cases with and without low-energy fractures were made by $\chi^{2}$ test or Fisher's exact test as formerly described.

Continuous data for age distributions and D vitamin levels in cases and controls were not normally distributed and compared using the nonparametric
Table 2. MECP2 mutation types according to nucleotide and amino acid changes and fracture occurrence in Danish patients with RTT

\begin{tabular}{|c|c|c|c|}
\hline $\begin{array}{c}\text { MECP } 2 \text { mutation types } \\
\text { Nucleotide change* (amino } \\
\text { acid change) }\end{array}$ & $\begin{array}{l}\text { Fractured } \\
\quad \text { cases } \\
n=14(\%)\end{array}$ & $\begin{array}{l}\text { Nonfractured } \\
\quad \text { cases } \\
n=47(\%)\end{array}$ & $p$ \\
\hline Early truncated for NLS & $4(29)$ & $18(38)$ & NS \\
\hline MECP2_e1:c.-47_57del11 & 1 & & \\
\hline Large deletions $\dagger$ & 2 & 2 & \\
\hline c.76delC & & 1 & \\
\hline c.382C > T (Q128X) & & 1 & \\
\hline c. $423 C>G(Y 141 X)$ & & 1 & \\
\hline c. $502 \mathrm{C}>\mathrm{T}(\mathrm{R} 168 \mathrm{X})$ & & 2 & \\
\hline c.753delC & & 1 & \\
\hline c. $763 \mathrm{C}>\mathrm{T}(\mathrm{R} 255 \mathrm{X})$ & 1 & 7 & \\
\hline c.779dup14 & & 1 & \\
\hline c.808delC & & 1 & \\
\hline c.803delG & & & \\
\hline c.808C > T (R270X) & & 1 & \\
\hline Late truncated for NLS & $1(7)$ & $6(13)$ & NS \\
\hline c.862del19 & & 1 & \\
\hline c. $880 \mathrm{C}>\mathrm{T}(\mathrm{R} 94 \mathrm{X})$ & 1 & 5 & \\
\hline $\mathrm{C}$ terminal & $2(14)$ & $8(17)$ & NS \\
\hline c. $1074 \mathrm{C}>\mathrm{G}, 1075 \mathrm{del} 7$ & 1 & & \\
\hline c. 1143 del 50 & & 1 & \\
\hline c.1150del38 & & 1 & \\
\hline c. 1155 del44 & & & \\
\hline c.1156del41 & 1 & & \\
\hline c.1156del44 & & 2 & \\
\hline c. $1157 \mathrm{del} 44$ & & 1 & \\
\hline c.1162del26 & & 1 & \\
\hline c. 1163 del 44 & & 1 & \\
\hline c.1163del11 & & 1 & \\
\hline c.1168del29 & & & \\
\hline Missense & $7(50)$ & $15(32)$ & NS: \\
\hline c.316C $>\mathrm{T}(\mathrm{R} 106 \mathrm{~W})$ & & 2 & \\
\hline c.397C > T (R133C) & 2 & 1 & \\
\hline c. $401 \mathrm{C}>\mathrm{G}(\mathrm{S} 134 \mathrm{C})$ & & 1 & \\
\hline c. $452 \mathrm{~A}>\mathrm{G}(\mathrm{D} 151 \mathrm{G})$ & & 1 & \\
\hline c. $455 \mathrm{C}>\mathrm{G}(\mathrm{P} 152 \mathrm{R})$ & & & \\
\hline c. $473 \mathrm{C}>\mathrm{T}(\mathrm{T} 158 \mathrm{M})$ & 2 & 9 & \\
\hline c.916C > T (R306C) & 2 & 1 & \\
\hline c. $925 \mathrm{C}>\mathrm{T}(\mathrm{R} 309 \mathrm{~W})$ & 1 & & \\
\hline
\end{tabular}

* The nucleotide change MECP2_e1:c.-47_57del11 was numbered according to NM_001110792.1.All other nucleotide changes were numbered according to NCBI Reference Sequence: NM_004992.3.

$\dagger$ Large deletions $=$ deletions including exon 3 and the coding region of exon 4.

$\$$ Pearson $\chi^{2}$, the rest is analyzed by Fisher's exact test.

Mann-Whitney $U$ test. The $\chi^{2}$ tests were applied for comparing proportions of $D$ vitamin samples in summer and winter among cases and controls.

Kappa coefficients, $\kappa$, were used to test intrarater reliability of categorical questionnaire items on potential fracture risk factors. The $\kappa$ values $>0.70$ were considered acceptable. Two sited levels of $p<0.05$ were considered significant. Calculations were performed with commercial software (SPSS, version 17.0, Chicago, IL).

Calculation of sample size. A case-control ratio of 1:2 was chosen to minimize the risk of a type 2 error. Calculation was based on a risk of a type 1 error of $5 \%$ and a risk of a type 2 error of $85 \%$. With an estimated $2 \%$ fracture incidence in the control group and an estimated fracture proportion of $30 \%$ in the case group, unequal sample size calculations recommended a minimum number of 48 controls and 24 cases (21).

Information and ethical aspects. Informed consent and assent were received from all participants according to the guidelines of the local ethics committee. The study was approved by the Danish Data Protection Agency and the local ethics committee and performed according to the Helsinki Declaration. 


\section{RESULTS}

A total of 61 cases with RTT and 122 healthy controls participated in this study. Distribution of age, puberty, and menstruation status was equal among cases and controls (Table 1) (17). Of cases, $57.4 \%$ aged $6-25$ y and $42.6 \%$ aged $26-60 \mathrm{y}$. Because of the growth retardation in RTT, controls were not matched by height and weight.

Table 2 shows the distribution of mutation types of included Rett cases. Included and nonincluded cases with RTT did not show significant different distributions of mutation types, $p=$ NS (Fig. 1).

According to the NPR, $13.1 \%$ (8 of 61 ) of cases and $17.2 \%$ (21 of 122) of controls experienced a fracture, of which the cases sustained $21.3 \%$ (13 of 61) fractures and the controls sustained $18.9 \%$ (23 of 122) fractures. Additional fractures were reported in the questionnaire for $9.8 \%$ (6 of 61) of cases and $6.6 \%$ (8 of 122) of controls adding $14.8 \%$ (9 of 61) fractures among cases and $8.2 \%$ (10 of 122) fractures among controls. Simultaneous fractures were not found.

No fractures of the spine were registered in the NPR or reported in the questionnaire. In the eldest Rett case, x-ray examination showed vertebral compressions of $>20 \%$ of the total vertebral height involving five vertebras. Fracture mechanism was unknown. Among controls, 17 had VFA done with no evidence of fractures, and one had a supplementary x-ray of the spine taken without fracture signs.

There was no significant difference between the relative number of cases and controls sustaining fractures and no significant difference between the two groups as to fracture events (Table 3). Significant differences were found concerning low-energy fractures between cases and controls in number of persons and as fracture events (Table 3 ).

Tables 4 and 5 summarize the types and distribution of fractures. Cases tended to fracture mostly the lower limb by low-energy mechanisms, whereas controls tended to fracture mostly the upper limb by high-energy mechanisms.

The first nonvertebral fracture event occurred for most cases, $77.3 \%$ (17 of 22), and controls, $81.8 \%$ (27 of 33), younger than $15 \mathrm{y}$. Regarding low-energy fractures, $91.7 \%$ (11 of 12) of cases and $62.5 \%$ (5 of 8) of controls with low-energy fractures sustained such a fracture before the age of $15 \mathrm{y}$. No significant difference was seen in fracture occurrence between the different categories of mutation types (Table 2).

The current age of cases with low-energy fractures was significantly higher than that of cases without low-energy

Table 3. Fracture occurrence among cases $(\mathrm{n}=61)$ and controls $(\mathrm{n}=122)$

\begin{tabular}{lcccc}
\hline & $\begin{array}{c}\text { Cases*, } \\
n(\%)\end{array}$ & $\begin{array}{c}\text { Controls*, } \\
n(\%)\end{array}$ & OR $(95 \%$ CI $)$ & $p^{\dagger}$ \\
\hline All fractures & & & & NS \\
$\quad$ Fracture persons & $23.0(14)$ & $23.8(29)$ & $0.96(0.46-1.98)$ & \\
$\quad$ Fracture events & $36.1(22)$ & $27.0(33)$ & $1.52(0.79-2.94)$ & \\
Low-energy fractures & & & & 0.007 \\
$\quad$ Fracture persons & $19.7(12)$ & $6.6(8)$ & $3.49(1.34-9.07)$ & \\
$\quad$ Fracture events & $31.1(19)$ & $7.4(9)$ & $5.68(2.38-13.54)$ & \\
\hline
\end{tabular}

\footnotetext{
$*$ Absolute numbers are provided in parenthesis.
}

$\dagger p=$ Pearson $\chi^{2}$ test.
Table 4. Low-energy nonvertebral fracture distribution, localization, and mechanism

\begin{tabular}{lccc}
\hline & \multicolumn{2}{c}{ Low-energy fractures } & \\
\cline { 2 - 3 } \multicolumn{1}{c}{ Fracture localization } & $\begin{array}{c}\text { Cases with } \\
\text { fractures* }\end{array}$ & $\begin{array}{c}\text { Controls with } \\
\text { fractures } \dagger\end{array}$ & $p \neq$ \\
\hline Humeral bone & 4 & 0 & 0.012 \\
Ulnar and radial bones & 3 & 5 & NS \\
Femural bone & 5 & 0 & 0.004 \\
Tibial, fibulal, and patellal bones & 3 & 3 & NS \\
\hline
\end{tabular}

* Twelve cases had a low-energy fracture: five cases had $>1$ nonsimultaneous fracture event. These were randomly distributed among the four fracture localizations.

$\dagger$ One control had two nonsimultaneous low-energy fractures of the ulnar and radial bones.

\$ Fisher's exact test: comparison of number of cases and controls with low-energy fractures.

Table 5. High-energy nonvertebral fracture distribution, localization, and mechanism

\begin{tabular}{lccc}
\hline & \multicolumn{2}{c}{ High-energy fractures } & \\
\cline { 2 - 3 } \multicolumn{1}{c}{ Fracture localization } & $\begin{array}{c}\text { Cases with } \\
\text { fractures* }\end{array}$ & $\begin{array}{c}\text { Controls with } \\
\text { fractures } \dagger\end{array}$ & $p \neq$ \\
\hline Humeral bone & 1 & 5 & NS \\
Ulnar and radial bones & 1 & 13 & 0.037 \\
Femural bone & 0 & 3 & NS \\
Tibial, fibulal, and patellal bones & 0 & 1 & NS \\
\hline
\end{tabular}

* One case had two nonsimultaneous high-energy fractures of the ulnar and radial bones.

$\dagger$ Twenty-one controls had a high-energy fracture: two controls had $>1$ nonsimultaneous fracture event.

\$ Fisher's exact test: comparison of number of cases and controls with high-energy fractures.

Table 6. Distribution of 25-OH vitamin D levels among cases and controls

\begin{tabular}{lccc}
\hline \multicolumn{1}{c}{ Blood sampling* } & Cases $\dagger$ & Controls $\dagger$ & $p \ddagger$ \\
\hline Summer§ & $n=28$ & $n=72$ & \\
Median (range), nmol/L & $43(14-101)$ & $71(20-186)$ & $<0.001$ \\
Winter|| & $n=31$ & $n=50$ & \\
Median (range), nmol/L & $62(10-177)$ & $49(14-156)$ & NS \\
\hline
\end{tabular}

$*$ No significant difference between winter or summer blood sampling was seen among cases and controls in general $(p=$ NS) or regarding to fractures $(p=\mathrm{NS}) ; p=$ Pearson $\chi^{2}$.

$\dagger 25-\mathrm{OH}$ vitamin D levels were significantly different between summer time and winter time for both cases $(p=0.046)$ and controls $(p<0.001) . p=$ Mann-Whitney $U$ test.

$\$ p=$ Mann-Whitney $U$ test.

$\S$ Obtained blood samples in summer: April 1 to October 15.

|| Obtained blood samples in winter: October 16 to March 31.

fractures, $32(8-61)$ y and $16(6-55) \mathrm{y}$, respectively, $p=$ 0.039 . There was no relation to age distributions among the different mutation types. In all four groups, $50 \%$ of cases were older than 30 y (data not shown). Patients with RTT had significantly lower $\mathrm{p}-25-\mathrm{OH}$ vitamin $\mathrm{D}$ levels during summertime but not during wintertime when compared with healthy controls (Table 6). In total, 21\% (3 of 14) of cases and 24\% (7 of 29) of controls with fractures had current $\mathrm{p}-25-\mathrm{OH}$ vitamin D levels below $50 \mathrm{nmol} / \mathrm{L}, p=1.000$.

Validation of questionnaire items regarding possible fracture risk factors showed no difference between first and later 
Table 7. Risk factors associated with low-energy fractures among cases with Rett syndrome

\begin{tabular}{|c|c|c|c|}
\hline Fracture risk factors & $\begin{array}{l}\text { Cases with } \\
\text { fractures } \\
(n=12)\end{array}$ & $\begin{array}{l}\text { Cases without } \\
\text { fractures } \\
(n=49)\end{array}$ & $p$ \\
\hline \multicolumn{4}{|l|}{ Currently walking, $n(\%)$} \\
\hline Independently & $2(16.7)$ & $26(53.1)$ & $0.023 *$ \\
\hline With light-massive support & $5(41.7)$ & $16(32.7)$ & \\
\hline Not & $5(41.7)$ & $7(14.3)$ & 0.047 \\
\hline \multicolumn{4}{|l|}{ Currently standing, $n(\%)$} \\
\hline Independently & $2(16.7)$ & $28(57.1)$ & $0.012 *$ \\
\hline With light-massive support & $7(58.3)$ & $20(40.8)$ & \\
\hline Not & $3(25.0)$ & $1(2.0)$ & 0.022 \\
\hline \multicolumn{4}{|l|}{ Currently sitting, $n(\%)$} \\
\hline $\begin{array}{l}\text { Independently or with light } \\
\text { support }\end{array}$ & $5(41.7)$ & $41(83.7)$ & 0.006 \\
\hline $\begin{array}{l}\text { Not or with massive } \\
\text { support }\end{array}$ & $7(58.3)$ & $8(16.3)$ & 0.006 \\
\hline \multicolumn{4}{|l|}{$\begin{array}{l}\text { Fall tendency within } 6 \\
\text { month, } n(\%)\end{array}$} \\
\hline$<1$ fall a month & $11(91.7)$ & $41(83.7)$ & NS \\
\hline$\geq 1$ fall a month & $1(8.3)$ & $8(16.3)$ & NS \\
\hline \multicolumn{4}{|l|}{$\begin{array}{l}\text { Best acquired ability to walk, } \\
n(\%)\end{array}$} \\
\hline Walking independently & $6(50.0)$ & $30(61.2)$ & NS \\
\hline Walking with support & $1(8.3)$ & $13(26.5$ & \\
\hline Never learned to walk & $5(41.7)$ & $6(12.2)$ & 0.031 \\
\hline \multicolumn{4}{|l|}{ Diagnosis of epilepsy, $n(\%)$} \\
\hline Ever & $9(75.0)$ & $38(77.6)$ & NS \\
\hline Never & $3(25.3)$ & $11(22.4)$ & NS \\
\hline
\end{tabular}

* Pearson $\chi^{2}$, the rest is analyzed by Fisher's exact test.

given answers. Kappa coefficients, $\kappa$ were all 1.00, except the value regarding fall tendency, $\kappa=0.71$ (95\% CI, 0.43-0.99). Concerning low-energy fractures, significant associations were shown for ability to walk, stand, sit, and never having learned to walk, but no associations were found regarding falls, a diagnosis of epilepsy, current seizures, or current or past treatment with AED (Table 7).

\section{DISCUSSION}

The most striking finding in this study was the significant increased OR for low-energy fractures among patients with RTT. In total, 12 of 61 Rett cases experienced 19 low-energy fractures, whereas 8 of 122 controls had 9 low-energy fractures. Controls experienced significantly more high-energy fractures compared with cases. This is the first time fracture mechanism is described within RTT.

As shown earlier $(8,9,22-24)$, we also found a greater frequency of lower limb fractures within RTT and more upper limb fractures among controls. Vertebral fractures were not common in our study, because we only identified vertebral fractures in our oldest patient aged $60 \mathrm{y}$.

Previous results report that the most commonly fractured region in normal children is the forearm (22-24) and that fractures in childhood often are due to sport and playing activities involving mild-moderate trauma $(22,25,26)$.

The profile of low-energy fractures among patients with RTT is in accordance with shown associations to current mobility and weight bearing status. Significantly, more fractured patients in our study were not walking, standing, and sitting independently compared with nonfractured patients. Furthermore, the occurrence of low-energy fractures was significantly associated with never having walked. This is in accordance with a 2-fold increase as to the first fracture event found among nonambulant patients in an Australian Rett population (9).

However, we did not find an association between lowenergy fractures and ever having walked independently. This might be confounded by the lack of fall tendency in our study, as most patients with RTT never fell. As a group, patients with RTT have reduced mobility (27), live in a protected environment, and are seldom left unattended. They may not be at true risk of falling when standing and walking.

The validation of questionnaire-derived fracture risk factors in terms of reliability was based on a rather small number (16\%), but despite uncertainty within smaller samples, the high values of the kappa coefficients indicated an acceptable level of intrarater agreement among cases.

Frequent low-energy fractures have been documented in other severely handicapped groups such as patients with cerebral palsy, who also show a predominance of fractures in the lower limb $(28,29)$ and significant associations between fracture occurrence and decreased ambulatory status (30).

In this study, we could not confirm an overall increased occurrence of fractures among the Danish patients with RTT. Only 14 of 61 patients sustained at least one fracture. However, the observed fracture occurrence among cases in our study is based on minimum numbers. Older cases may have sustained fractures unknown to current nonparental caregivers or too early to be registered in the NPR. Life-long medical records could not be retrieved for the oldest cases. Furthermore, only fractures with an assumed high degree of correct diagnosis were included.

A combination of register search and questionnaire reported data seemed to be relevant in our retrospective study, because fractures registered in the NPR were not always apparent from the questionnaire and vice versa. Among controls, 3 of 23 fracture events registered in the NPR were not reported in the questionnaire, and conversely 10 of 33 reported fracture events were not registered in the NPR. Of these, 6 of 10 fracture events occurred before registration in the NPR was complete and valid from 1977 to 1778 .

To date, only one study has examined fracture incidence in a Rett population compared with the general population (8). The study showed a 4-fold increased risk of fractures within RTT with a calculated incidence of 433 fracture events per 10,000 person years.

Our study has the strength of a sex, age, and pubertal/ menopausal-matched control group. We find that our control data are comparable with other studies $(24,31)$. We calculated the occurrence of fracture events per 10,000 person years to be 180 for cases and 135 for controls, as estimated from a median age of $20 \mathrm{y}$ in both groups in our study. An incidence of 189 per 10,000 person years of fracture events in the background population was recorded for both sexes in another area of Denmark in 2003 based on emergency room contacts (31). Regarding females, fracture incidence was 103 per 10,000 
person years among healthy females younger than $18 \mathrm{y}$ in a British population (24).

Most fracture events occurred before the age of $15 \mathrm{y}$ for both groups in our study. In the background, population fractures peak in youth and in the elderly (32).

According to Australian data, patients with RTT have a fracture risk of $38-42 \%$ by the age of $15 \mathrm{y}(8,9)$. Among healthy children, one study found that $40 \%$ of girls sustained fractures throughout growth (23). These data indicate that comparison of fracture risks and incidences rates within RTT is relative. Furthermore, fracture occurrence may not be comparable because of the different fracture mechanisms.

Predominance of childhood fractures within RTT implies that bone modeling may be affected. A histomorphometric study of four girls with RTT suggested a slow rate of bone formation (33).

However, having sustained a low-energy fracture at an early age did not necessarily affect the chance of achieving older age, because cases with low-energy fractures were currently older than cases without low-energy fractures. Furthermore, the age difference could not be explained by overrepresentation of specific mutation types. We had a rather large proportion $(42.6 \%)$ of patients with RTT older than $25 \mathrm{y}$ in our study, which is in accordance with estimates of longevity into middle age within Rett populations $(34,35)$.

We found no association between the mutation types and fracture distribution in our study, in contrast to an Australian study demonstrating a 3-fold increased fracture risk specific for patients with RTT with a p.R270× mutation compared with patients with RTT with no mutation. The lack of association in our study may be caused by the actual number of different MECP2 mutations, even though our mutation type distributions as to early and late truncated mutations for NLS, C-terminal mutations, and missense mutations were almost identical to the Australian study (8). A weakness of both studies is the lacking information regarding $\mathrm{X}$-chromosome inactivation (36,37). The issue regarding genotype and fracture occurrence within RTT and the role of bone metabolism being targeted by MeCP2 are in need of further studies. In general, a diagnosis of epilepsy and use of AED have been reported to be related to fracture occurrence $(38,39)$, but the issue is debated (40-42).

We found no association between epilepsy, antiepileptic treatment, and fracture occurrence among our patients in contrast to others $(8,9,16)$.

Lacking of associations within our dataset might be explained by a high total proportion (47 of 61) of patients with RTT with a diagnosis of epilepsy ever. In an American cohort (43), a lower proportion of $60 \%$ was found and it decreased to $48 \%$ when estimated by a physician. Epileptic seizures might be misdiagnosed within RTT $(44,45)$.

Regarding vitamin D status, our findings showed a significant lower level of vitamin D among cases compared with controls during summertime but not during wintertime. The reason for this could be lack of sunshine exposure for patients with RTT during the summer. For comparison, vitamin D $<50$ $\mathrm{nmol} / \mathrm{L}$ during winter has been estimated for $50 \%$ of normal blood donors in Denmark (reference population, Clinical Bio- chemical Department, Århus Hospital) (46). Our data imply a need for all year supplementation.

A low level of vitamin D is known within RTT $(11,14)$. Vitamin D status should be evaluated in these patients, because vitamin D deficiency is associated with proximal myopathy and reduced mineralization of the bones (47). Sparse literature can be found concerning children and young adults, but proximal myopathy and reduced bone strength would be problematic in our Rett population because of the increased occurrence of low-energy fractures especially of the femur and humerus.

Early and continuous weight bearing, mechanical loading, and daily physical activity is expected to be important to modify muscle functioning within RTT and stimulate bone modeling, growth, and strength.

In conclusion, we found no increased overall fracture occurrence among Danish patients with RTT compared with our control group, but the fracture mechanism was significantly different. Patients with RTT sustained low-energy fractures in the lower limb at an early age from normal daily activity.

Reduced current mobility and lack of ambulation at any point of life was associated with a fracture history. Increased knowledge of bone pathology and fracture prevention within RTT is important and should be addressed in future studies.

Acknowledgments. We thank the Danish patients with RTT, their families and caregivers, and all control persons and their families for participation in the project. We also thank the Danish Association of RTT for supporting the project. We thank Pernille Strøm and Mette Lisa Jørgensen at the Kennedy Center for handling of questionnaire data and project logistic. We also thank Anne Mette Rasmussen at the Endocrinological Department, Hvidovre Hospital, for controlling the flow of examinations at Hvidovre Hospital for cases and controls.

\section{REFERENCES}

1. Amir RE, Van den Veyer IB, Wan M, Tran CQ, Francke U, Zoghbi HY 1999 Rett syndrome is caused by mutations in X-linked MECP2, encoding methyl-CpGbinding protein 2. Nat Genet 23:185-188

2. Nielsen JB 1999 [Rett Syndrome: Progressive Neurodegeneration or Neuronal Developmental Defect? Prevalence, Clinical Evaluation and Pathogenesis]. LEV, Hvidovre, Denmark, pp 10-13

3. Hagberg B, Hanefeld F, Percy A, Skjeldal O 2002 An update on clinically applicable diagnostic criteria in Rett syndrome. Comments to Rett Syndrome Clinical Criteria Consensus Panel Satellite to European Paediatric Neurology Society Meeting, Baden Baden, Germany, 11 September 2001. Eur J Paediatr Neurol 6:293-297

4. Hagberg BA, Skjeldal OH 1994 Rett variants: a suggested model for inclusion criteria. Pediatr Neurol 11:5-11

5. Hagberg B 2002 Clinical manifestations and stages of Rett syndrome. Ment Retard Dev Disabil Res Rev 8:61-65

6. Schultz RJ, Glaze DG, Motil KJ, Armstrong DD, del Junco DJ, Hubbard CR, Percy AK 1993 The pattern of growth failure in Rett syndrome. Am J Dis Child 147:633-637

7. Bebbington A, Anderson A, Ravine D, Fyfe S, Pineda M, de Klerk N, Ben Zeev B, Yatawara N, Percy A, Kaufmann WE, Leonard H 2008 Investigating genotypephenotype relationships in Rett syndrome using an international data set. Neurology 70:868-875

8. Downs J, Bebbington A, Woodhead H, Jacoby P, Jian L, Jefferson A, Leonard H 2008 Early determinants of fractures in Rett syndrome. Pediatrics 121:540-546

9. Leonard H, Thomson MR, Glasson EJ, Fyfe S, Leonard S, Bower C, Christodoulou J, Ellaway C 1999 A population-based approach to the investigation of osteopenia in Rett syndrome. Dev Med Child Neurol 41:323-328

10. Haas RH, Dixon SD, Sartoris DJ, Hennessy MJ 1997 Osteopenia in Rett syndrome. J Pediatr 131:771-774

11. Cepollaro C, Gonnelli S, Bruni D, Pacini S, Martini S, Franci MB, Gennari L, Rossi S, Hayek G, Zappella M, Gennari C 2001 Dual X-ray absorptiometry and bone ultrasonography in patients with Rett syndrome. Calcif Tissue Int 69:259-262 
12. Motil KJ, Schultz RJ, Abrams S, Ellis KJ, Glaze DG 2006 Fractional calcium absorption is increased in girls with Rett syndrome. J Pediatr Gastroenterol Nutr 42:419-426

13. Zysman L, Lotan M, Ben Zeev B 2006 Osteoporosis in Rett syndrome: a study on normal values. ScientificWorldJournal 6:1619-1630

14. Gonnelli S, Caffarelli C, Hayek J, Montagnani A, Cadirni A, Franci B, Lucani B, Rossi S, Nuti R 2008 Bone ultrasonography at phalanxes in patients with Rett syndrome: a 3-year longitudinal study. Bone 42:737-742

15. Motil KJ, Ellis KJ, Barrish JO, Caeg E, Glaze DG 2008 Bone mineral content and bone mineral density are lower in older than in younger females with Rett syndrome. Pediatr Res 64:435-439

16. Leonard H, Downs J, Jian L, Bebbington A, Jacoby P, Nagarajan L, Ravine D, Woodhead H 2010 Valproate and risk of fracture in Rett syndrome. Arch Dis Child 95:444-448

17. Marshall WA, Tanner JM 1969 Variations in pattern of pubertal changes in girls. Arch Dis Child 44:291-303

18. The Danish National Board of Health [register declaration for the National Patient Registry]. Available at: http://www.sst.dk. Accessed, November 23, 2009

19. Genant HK, Wu CY, van Kuijk C, Nevitt MC 1993 Vertebral fracture assessment using a semiquantitative technique. J Bone Miner Res 8:1137-1148

20. Grados F, Fechtenbaum J, Flipon E, Kolta S, Roux C, Fardellone P 2009 Radiographic methods for evaluating osteoporotic vertebral fractures. Joint Bone Spine 76:241-247

21. Altman DG 1991 Practical Statistics For Medical Research. Chapman \& Hall, London, pp 455-460

22. Brudvik C, Hove LM 2003 Childhood fractures in Bergen, Norway: identifying high-risk groups and activities. J Pediatr Orthop 23:629-634

23. Jones IE, Williams SM, Dow N, Goulding A 2002 How many children remain fracture-free during growth? A longitudinal study of children and adolescents participating in the Dunedin Multidisciplinary Health and Development Study. Osteoporos Int 13:990-995

24. Cooper C, Dennison EM, Leufkens HG, Bishop N, van Staa TP 2004 Epidemiology of childhood fractures in Britain: a study using the general practice research database. J Bone Miner Res 19:1976-1981

25. Landin LA 1983 Fracture patterns in children. Analysis of 8,682 fractures with special reference to incidence, etiology and secular changes in a Swedish urban population 1950-1979. Acta Orthop Scand Suppl 202:1-109, 1983

26. Goulding A 2007 Risk factors for fractures in normally active children and adolescents. Med Sport Sci 51:102-120

27. Cass H, Reilly S, Owen L, Wisbeach A, Weekes L, Slonims V, Wigram T, Charman T 2003 Findings from a multidisciplinary clinical case series of females with Rett syndrome. Dev Med Child Neurol 45:325-337

28. Presedo A, Dabney KW, Miller F 2007 Fractures in patients with cerebral palsy. J Pediatr Orthop 27:147-153

29. Leet AI, Mesfin A, Pichard C, Launay F, Brintzenhofeszoc K, Levey EB, Sponseller D 2006 Fractures in children with cerebral palsy. J Pediatr Orthop 26:624-627
30. Cohen M, Lahat E, Bistritzer T, Livne A, Heyman E, Rachmiel M 2009 Evidencebased review of bone strength in children and youth with cerebral palsy. J Child Neurol 24:959-967

31. Larsen LB, Larsen MS, Lauritsen JM 2003 [Accidents 2003. Accident victims treated at the A \& E department, Odense University Hospital]. Available at: http://www.teamtext.dk/uag/pdfs/2003.pdf. Accessed, May 10, 2010

32. Cooley HM, Jones G 2002 Symptomatic fracture incidence in southern Tasmania: does living in the country reduce your fracture risk? Osteoporos Int 13:317-322

33. Budden SS, Gunness ME 2003 Possible mechanisms of osteopenia in Rett syndrome: bone histomorphometric studies. J Child Neurol 18:698-702

34. Laurvick CL, de Klerk N, Bower C, Christodoulou J, Ravine D, Ellaway C, Williamson S, Leonard H 2006 Rett syndrome in Australia: a review of the epidemiology. J Pediatr 148:347-352

35. Kirby RS, Lane JB, Childers J, Skinner SA, Annese F, Barrish JO, Glaze DG, Macleod P, Percy AK 2010 Longevity in Rett syndrome: analysis of the North American Database. J Pediatr 156:135-138

36. Ham AL, Kumar A, Deeter R, Schanen NC 2005 Does genotype predict phenotype in Rett syndrome? J Child Neurol 20:768-778

37. Nielsen JB, Henriksen KF, Hansen C, Silahtaroglu A, Schwartz M, Tommerup N 2001 MECP2 mutations in Danish patients with Rett syndrome: high frequency of mutations but no consistent correlations with clinical severity or with the $\mathrm{X}$ chromosome inactivation pattern. Eur J Hum Genet 9:178-184

38. Vestergaard P, Tigaran S, Rejnmark L, Tigaran C, Dam M, Mosekilde L 1999 Fracture risk is increased in epilepsy. Acta Neurol Scand 99:269-275

39. Vestergaard P, Rejnmark L, Mosekilde L 2004 Fracture risk associated with use of antiepileptic drugs. Epilepsia 45:1330-1337

40. Pack A 2008 Bone health in people with epilepsy: is it impaired and what are the risk factors? Seizure 17:181-186

41. Samaniego EA, Sheth RD 2007 Bone consequences of epilepsy and antiepileptic medications. Semin Pediatr Neurol 14:196-200

42. Petty SJ, O'Brien TJ, Wark JD 2007 Anti-epileptic medication and bone health. Osteoporos Int 18:129-142

43. Glaze DG, Percy AK, Skinner S, Motil KJ, Neul JL, Barrish JO, Lane JB, Geerts SP, Annese F, Graham J, McNair L, Lee HS 2010 Epilepsy and the natural history of Rett syndrome. Neurology 74:909-912

44. Julu PO, Engerstrom IW, Hansen S, Apartopoulos F, Engerstrom B, Pini G, Delamont RS, Smeets EE 2008 Cardiorespiratory challenges in Rett's syndrome. Lancet 371:1981-1983

45. Moser SJ, Weber P, Lutschg J 2007 Rett syndrome: clinical and electrophysiologic aspects. Pediatr Neurol 36:95-100

46. Mosekilde L, Nielsen LR, Larsen ER, Moosgaard B, Heickendorff L 2005 Vitamin D deficiency. Definition and prevalence in Denmark [in Danish]. Ugeskr Laeger 167:29-33

47. Mosekilde L 2008 Vitamin D requirement and setting recommendation levels: long-term perspectives. Nutr Rev 66:S170-S177 